\title{
Adaptation of outpatient cardiovascular rehabilitation in Zagreb to the emerging conditions due to the COVID-19 pandemic and the large earthquake in March
}

\author{
(iD) Mario Ivanuša ${ }^{1,2}$ \\ 'Institute for Cardiovascular \\ Prevention and \\ Rehabilitation, Zagreb, \\ Croatia \\ ${ }^{2}$ Univesity of Rijeka, Faculty of \\ Medicine, Rijeka, Croatia
}

KEYWORDS: cardiac rehabilitation, secondary prevention, COVID-19, earthquake, Croatia. CITATION: Cardiol Croat. 2021;16(1-2):55-6. | https://doi.org/10.15836/ccar2021.55

*ADDRESS FOR CORRESPONDENCE: Mario Ivanuša, Poliklinika za prevenciju kardiovaskularnih bolesti i rehabilitaciju, Draškovićeva 13, HR-10000 Zagreb, Croatia. / Phone: +385-1-4612-290 / E-mail: mivanusa@gmail.com

ORCID: Mario Ivanuša, https://orcid.org/0000-0002-6426-6831

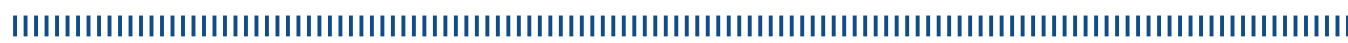

\begin{abstract}
The COVID-19 pandemic and the that hit Zagreb in March not only reduced the availability of health care and caused higher morbidity and mortality in the population of the Republic of Croatia, but also limited the use of secondary prevention measures in cardiovascular (CV) patients. These high-risk patients were faced with a drastic change in the quantity and quality of daily activities, quarantine and isolation as a result of COVID-19, and fear of the consequences and uncertainty from a sudden earthquake, all leading to a health disruption. These rapid and significant changes in everyday life, especially in those who can marshal less mental resilience, have resulted in a deterioration of lifestyle habits and impairment of the quality of life. ${ }^{1}$ To adequately respond to the emerging conditions, the program of outpatient CV rehabilitation of the Srčana Institute for Cardiovascular Prevention and Rehabilitation in Zagreb embraced digitalization and reorganized its traditional patterns ${ }^{2}$ to implement a fully virtual program for the first time. The virtual program has been running for 60 days, and we will outline the full scope of adjustments made to the program since March until the end of 2020
\end{abstract}

During the period from March 23 to May 28, 2020, we used easy-to-reach methods of communication, such as telephone-delivered or text messaging interventions that we accompanied with structured therapeutic education and digital materials sent to CV patients by e-mail. Additionally, we dedicated a section on our web portal to publishing all digital content (PDF, mp4) with recorded medical exercises for CV patients and advice from psychologists and other members of the CV rehabilitation team, covering topics such as nutrition and other important information. ${ }^{3}$ To maintain patient engagement after the earthquake, 80 patients who remained virtually involved in the program were also included in the weekly newsletter program. ${ }^{4}$ Despite our focus on maintaining high engagement, five patients opted out of the program, which is still in line with our expectations.

Having restored conditions for the safe implementation of the program, we recommenced performing the traditional form of rehabilitation in our center (12 weeks, 36 sessions), starting with previously enrolled patients and followed by newly admitted patients two weeks after. In order to reduce the possibility of accidental infection of CV patients and healthcare professionals with COVID-19, we have adapted the organization and protocols of all therapeutic interventions, ensured the application of hygienic procedures and social distancing, and, in addition to the use of personal protective equipment, we have installed protective glass on reception desks (Figure 1). All visits to the Institute are recorded, and after measuring body temperature at the entrance and checking for negative epidemiological history, we acquaint visitors movement limitations that are currently in force in the institution. The program of outpatient CV rehabilitation, in accordance with the experience of other countries, has been adapted by focusing on the most important components of secondary prevention: risk stratification, correction of variable risk factors, psychosocial support, therapeutic education, and medical exercises. In this way, we strive to ensure the high quality of health care among high-risk CV patients.
RECEIVED:

November 30, 2020

ACCEPTED:

December 18, 2020

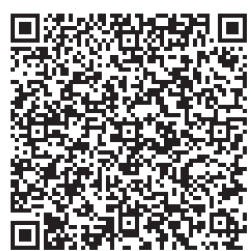

Cardiologia Croatica $\square$ 2021;16(1-2):55 
Adaptation of outpatient cardiovascular rehabilitation in Zagreb to the emerging

conditions due to the COVID-19 pandemic and the large earthquake in March
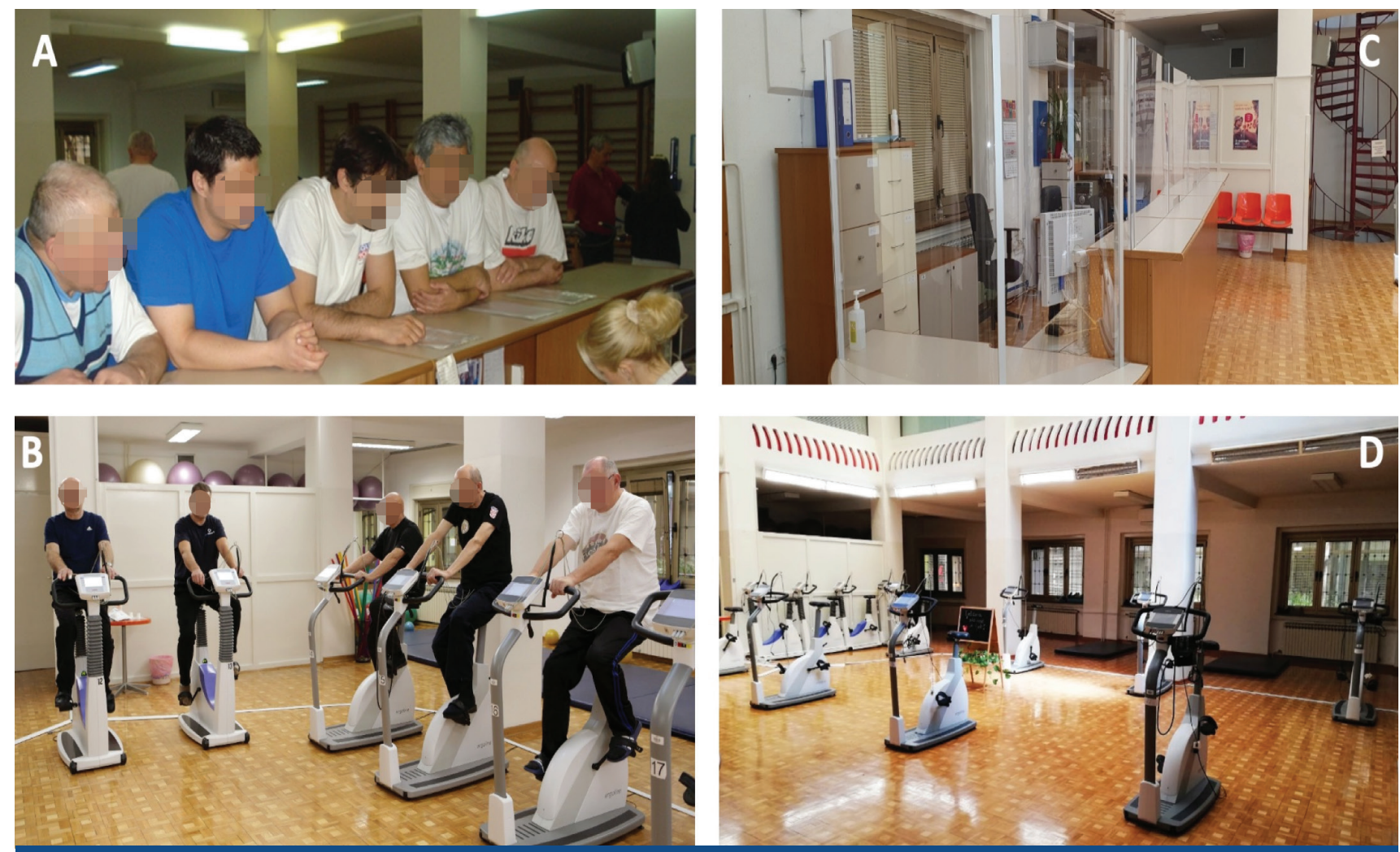

FIGURE 1. Organization of a medical gymnastics hall before (A, B) and after (C, D) the COVID-19 pandemic.

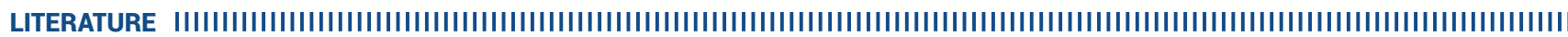

1. Peitl V, Golubić Zatezalo V, Karlović D. Mental Health Issues and Psychological Crisis Interventions During the COVID-19 Pandemic and Earthquakes in Croatia. Archives of Psychiatry Research 2020;56:193-198. https://doi.org/10.20471/dec.2020.56.02.07

2. Ivanuša M, Narančić Skorić K, Glavaš Vraží S, Kruhek Leontić D, Heinrich M, Mažuran Brkljačíć L, et al. Outpatient Cardiovascular Rehabilitation in Croatia. Cardiol Croat. 2015;10(1-2):28-42. https://doi.org/10.15836/ccar.2015.28

3. Poliklinika Srčana. Kardiovaskularna rehabilitacija u doba korone i potresa. https://www.srcana.hr/hr/novosti-i-dogadanja/korona/ (Nov 30, 2020)

4. Poliklinika Srčana. Newsletteri Srčana. https://www.srcana.hr/hr/newsletteri-srcana/ (Nov 30, 2020). 